\title{
SEQUÊNCIA DIDÁtICA PARA INSERÇÃo DA EDUCAÇÃ̃ AMBIENTAL NO ENSINO FUNDAMENTAL
}

\author{
DIDACTIC SEQUENCE FOR INSERTING ENVIRONMENTAL EDUCATION IN \\ FUNDAMENTAL EDUCATION
}

\section{SECUENCIA DIDÁCTICA PARA LA INSERCIÓN DE LA EDUCACIÓN AMBIENTAL EN LA ENSEÑANZA FUNDAMENTAL}

\author{
Márcia Belo Soares \\ E-mail: belomarcia@yahoo.com.br \\ Rita de Cássia Frenedozo \\ E-mail: ritafrenedozo@yahoo.com.br \\ Universidade Cruzeiro do Sul - UNICSUL/SP
}

\begin{abstract}
RESUMO
Este artigo teve como objetivo oferecer subsídios para trabalhar a Educação Ambiental de maneira crítica com alunos do Ensino Fundamental (anos iniciais). Através da ferramenta Sequência Didática (SD) trabalhou-se a inserção da temática ambiental visando à transformação de atitudes e conhecimentos acerca de práticas cotidianas que causam desequilíbrios ambientais. A pesquisa foi estruturada em 10 (dez) aulas e abordou temas ligados ao meio ambiente como: sustentabilidade, aumento populacional, recursos naturais e consumismo. Foram proporcionados momentos de ação e reflexão tornando a aprendizagem significativa. Os resultados apontaram que a proposta levou a formação do cidadão crítico capaz de refletir sobre suas responsabilidades e propor ações a serem desenvolvidas no coletivo e para o coletivo. Os alunos propuseram diversas ações visando transformar a sociedade e redefinir sua própria condição na natureza. A atividade promoveu o envolvimento de todos nas diferentes etapas propostas e possibilitou a reflexão quanto à viabilidade de trabalhar a Educação Ambiental de maneira critica no contexto educacional.
\end{abstract}

PALAVRAS-CHAVE: Educação Ambiental Crítica. Sequência Didática. Ensino Fundamental.

\section{ABSTRACT}

This article had as objective to offer subsidies to work the Environmental Education in a critical way with students of Elementary School (initial years). Through the Didactic Sequence (SD) tool, we worked on the insertion of the environmental theme in order to transform attitudes and knowledge about everyday practices that cause environmental imbalances. The research was structured in 10 (ten) classes and addressed themes related to the environment such as: sustainability, population growth, natural resources and consumerism. Moments of action and reflection were provided, making learning meaningful. The results showed that the proposal led to the formation of critical citizens capable of reflecting on their responsibilities and proposing actions to be developed in the collective and for the collective. The students proposed several actions aimed at transforming society and redefining its own condition in nature. The activity promoted the involvement of all in the different stages proposed and made possible the reflection on the feasibility of working Environmental Education in a critical way in the educational context.

KEY WORDS: Critical Environmental Education. Following teaching. Elementary School.

\section{RESUMEN}

Este artículo tuvo como objetivo ofrecer subsidios para trabajar la Educación Ambiental de manera crítica con alumnos de la Enseñanza Fundamental (años iniciales). A través de la herramienta Secuencia Didáctica (SD) se trabajó la inserción de la temática ambiental visando la transformación de actitudes y conocimientos acerca 
de prácticas cotidianas que causan desequilibrios ambientales. La encuesta fue estructurada en 10 (diez) lecciones y abordó temas relacionados al medio ambiente como: sostenibilidad, aumento poblacional, recursos naturales y consumismo. Se proporcionaron momentos de acción y reflexión haciendo el aprendizaje significativo. Los resultados apuntaron que la propuesta llevó la formación del ciudadano crítico capaz de reflexionar sobre sus responsabilidades y proponer acciones a ser desarrolladas en el colectivo y para el colectivo. Los alumnos propusieron diversas acciones para transformar la sociedad y redefinir su propia condición en la naturaleza. La actividad promovió la participación de todos en las diferentes etapas propuestas y posibilitó la reflexión en cuanto a la viabilidad de trabajar la Educación Ambiental de manera crítica en el contexto educativo.

PALABRAS CLAVE: Educación Ambiental Crítica. Secuencia Didáctica. Enseñanza fundamental.

\section{INTRODUÇÃ̃O}

Vivemos em um momento em que a educação é vista como uma das principais alternativas para tratar de assuntos relacionados às questões ambientais. A utilização desenfreada dos recursos naturais pelo homem ao longo dos anos faz com que o mesmo enfrente diversos problemas. O planeta evidencia não suportar mais o crescente aumento populacional, bem como, o consumismo dos dias atuais.

A Lei de Diretrizes e Bases da Educação Nacional-LDB apresenta uma preocupação com o desenvolvimento de atitudes que favoreçam ao educando a autonomia intelectual e seu pensamento crítico. É necessário um ensino voltado a Educação Ambiental que favoreça a sensibilização e a mudança de atitudes em relação à preservação do meio ambiente (BRASIL, 1996).

A temática ambiental ganhou força a partir da década de 60 , foram vários os debates, congressos e conferências que surgiram com o intuito de discutir de trazer a discussão da crise ambiental enfatizando a ideia da Educação Ambiental (DIAS, 2010).

Tanto a Conferência da Organização das Nações Unidas (ONU) realizada no ano de 1972 em Estocolmo-Suécia, como a I Conferência Intergovernamental sobre Educação para o Ambiente, realizada em 1977 em Tbilisi-Geórgia buscaram estabelecer orientações para a humanidade em relação à preservação e melhoria do ambiente humano (DIAS, 2010).

No Brasil, a Educação Ambiental ganhou maior relevância a partir da década de 1980 com a Conferência das Nações Unidas sobre o Meio Ambiente e Desenvolvimento, também conhecida como Rio-92, realizada no Rio de Janeiro. 


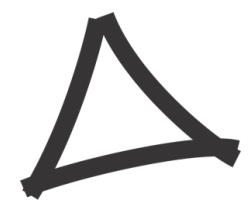

Em 2012, destaca-se a Conferência Rio+20, que teve como objetivo a renovação dos compromissos entre os políticos para o desenvolvimento sustentável e definiu a agenda do desenvolvimento sustentável para as próximas décadas, apontando preocupação com as condições de sobrevivência futura no planeta.

Nos PCNs - Parâmetros Curriculares Nacionais, desde 1998, o tema Meio Ambiente é considerado como um tema transversal e propõe no âmbito escolar a realização de trabalhos voltados para a implantação de uma Educação Ambiental que discuta situações relacionadas ao cotidiano dos alunos.

Contribuindo assim, para a formação do cidadão participativo, plenamente reconhecido e consciente de seu papel na sociedade (BRASIL, 1998).

Alguns autores afirmam que embora a Educação Ambiental não tenha um conceito único definido são as concepções que cada indivíduo tem sobre o ambiente que direcionam suas práticas pedagógicas utilizadas em sala de aula (SAUVÉ, 2005, REIGOTA, 2015; GUIMARÃES, 2015).

Reigota (2015) cita que a Educação Ambiental deve ser entendida como uma educação política que visa preparar o sujeito para o exercício da cidadania, sendo, portanto, condição indispensável para proporcionar a participação dos sujeitos nas relações sociais e com a natureza.

No cenário social atual a Educação Ambiental pode vir a se constituir como um possível recurso de transformação da realidade. Segundo Loureiro (2011, p.73) a "Educação Ambiental é uma práxis educativa e social que tem por finalidade a construção de valores, conceitos, habilidades e atitudes".

No processo educacional a Educação Ambiental deve apresentar discussões atuais sobre as questões ambientais, proporcionando novos conhecimentos, transformações de valores e atitudes ocasionando a construção de uma nova realidade (GUIMARÃES, 2015).

Portanto, cabe ao educador planejar suas ações e organizá-las objetivando alcançar os objetivos propostos e proporcionando aos alunos uma aprendizagem significativa.

As estratégias de ensino são facilitadoras do ensino aprendizagem e visa o envolvimento de atividades de reflexão, aprendizagem e de avaliação, por meio delas o educador planeja as etapas a serem seguidas e explora um conteúdo específico. Elas preveem uma progressão a partir dos conhecimentos prévios dos educandos sobre determinado 


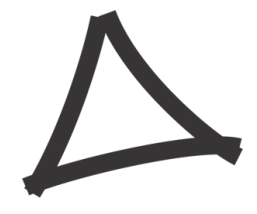

Revista Triângulo

www.seer.uftm.edu.br/revistaeletronica

conteúdo e possibilitam que progressivamente novos conhecimentos sejam adquiridos (BRASIL, 2012a).

Conforme Zabala (2010) a estratégia de ensino Sequência Didática (SD) é um conjunto de atividades organizadas e articuladas que apresentam um grau de dificuldade e visam à realização de determinados objetivos educacionais com um princípio e fim conhecido pelo educador e pelos educandos.

Neste contexto, nossa Sequência Didática intitulada "Educação Ambiental: Cidadania e Sustentabilidade" teve objetivo oferecer subsídios para trabalhar a Educação Ambiental de maneira crítica com alunos do $2^{\circ}$ ano do Ensino Fundamental (anos iniciais). As atividades visaram promover o ensino aprendizagem de maneira significativa e orientar os alunos em relação a práticas cotidianas que causam desequilíbrios ambientais.

\section{PROCEDIMENTOS METODOLÓGICOS}

A pesquisa foi desenvolvida em uma escola da rede municipal de Santo André - SP. A escola atende a demanda do próprio bairro e de bairros adjacentes, possui um total de 664 alunos, sendo 188 de Educação Infantil e 476 de Ensino Fundamental.

O público alvo foram os alunos do $2^{\circ}$ ano do Ensino Fundamental (anos iniciais), faixa etária entre 7 e 8 anos, a turma é constituída por 29 alunos. A atividade teve duração de 10 aulas de 60 minutos cada aula.

A Sequência Didática trabalhou a Educação Ambiental de maneira crítica, visando à transformação de atitudes e conhecimentos acerca de práticas cotidianas que causam desequilíbrios ambientais.

Foram trabalhados temas relacionados com a sustentabilidade, aumento populacional, recursos naturais e consumismo, possibilitando ao aluno compreender o ambiente onde vive e atuar nele como cidadão. Buscou-se a formação do pensamento crítico, levando-os a refletir sobre a questão: Sua escola pratica a sustentabilidade?

A escola sustentável é aquela que valoriza a diversidade e estabelece conexões entre a sala de aula e os diversos saberes. Ela incentiva a cidadania ambiental, estimulando a responsabilidade e o engajamento individual e coletivo na transformação local e global. É um 


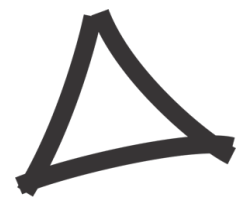

Revista Triângulo

www.seer.uftm.edu.br/revistaeletronica

espaço que permite a incorporação ao cotidiano dos educandos e atitudes voltadas à preservação do meio ambiente (BRASIL, 2012b).

A Sequência Didática foi organizada e desenvolvida em 10 aulas, conforme quadro 1.

Quadro 1 - Sequência Didática "Educação Ambiental: Cidadania e Sustentabilidade"

\begin{tabular}{|c|c|c|}
\hline Número de Aulas & Momentos & Atividades Propostas \\
\hline 3 & Problematização & $\begin{array}{l}\text {-Apresentação da proposta de trabalho } \\
\text {-Roda de conversas sobre conhecimentos prévios: } \\
\text { 1) O que é meio ambiente? } \\
\text { 2) O que são Recursos Naturais? } \\
\text { 3)O que é Desenvolvimento Sustentável? } \\
\text {-Reflexão sobre a questão: Sua escola pratica a } \\
\text { sustentabilidade? }\end{array}$ \\
\hline 4 & Organização & $\begin{array}{l}\text {-Livro Os heróis e o consumo consciente de Beatriz } \\
\text { Monteiro da Cunha (2011) } \\
\text {-Exibição vídeo Recursos Naturais e debate } \\
\text {-Exibição do filme Wall-E e debate } \\
\text {-Pesquisas sobre fontes de energia e debate } \\
\text {-Aula prática investigativa e aplicação do } \\
\text { questionário (anexo 1) sobre a questão: Sua escola } \\
\text { pratica a sustentabilidade? }\end{array}$ \\
\hline 3 & Aplicação & $\begin{array}{l}\text {-Em grupos produção de desenhos sobre recursos } \\
\text { naturais e meio ambiente. } \\
\text {-Exposição dos desenhos } \\
\text {-Confecção e exposição dos gráficos com os } \\
\text { resultados dos questionários } \\
\text {-Apresentação de algumas ações para a escola } \\
\text { visando à sustentabilidade } \\
\text {-Apresentação dos resultados à Coordenação e } \\
\text { demais alunos da escola } \\
\text {-Sistematização e fechamento da proposta }\end{array}$ \\
\hline
\end{tabular}

Fonte: Elaborado pelas pesquisadoras 


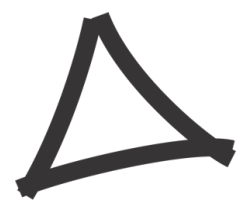

A atividade contou com os seguintes momentos: problematização inicial objetivando identificar os conhecimentos prévios dos alunos; organização dos conhecimentos e aplicação dos conhecimentos adquiridos.

O $1^{\circ}$ momento problematização inicial: teve duração de 3 aulas. Nele foi apresentada a proposta do trabalho aos alunos, após realizamos uma roda de conversas sobre as questões: 1) O que é meio ambiente? 2) O que são Recursos Naturais? 3) O que é Desenvolvimento Sustentável? Neste momento, aos alunos também puderam refletir sobre a questão: Sua escola pratica a sustentabilidade?

No $2^{\circ}$ momento organização dos conhecimentos: foram trabalhados alguns temas para compreensão da problematização inicial. Trabalhamos o livro Os heróis e o consumo consciente de Beatriz Monteiro da Cunha que trata da questão do consumo consciente, o papel das propagandas e a questão dos recursos naturais (CUNHA, 2011).

Posteriormente, foi exibido um vídeo que abordou as questões dos Recursos Naturais (renováveis e não renováveis) e serviu de suporte para as discussões sobre as relações de produção e consumo e sobre a transformação, utilização e comercialização de alguns bens de consumo no nosso cotidiano. A exibição do filme Wall-E teve como foco a discussão sobre questões relacionadas ao meio ambiente e consumismo, ele também relatou de forma clara os efeitos do consumismo e geração de lixo para o planeta.

Após, visando responder a questão focal da pesquisa: Sua escola pratica a sustentabilidade?, a educadora fez questionamentos aos alunos sobre as ações de sustentabilidade praticadas na escola, como: consumo de energia elétrica e água; desperdício de materiais utilizados pelos professores, por colegas de sala, funcionários da escola; reciclagem; projeto horta, alimentação saudável e desperdício de alimentos, bem como, se na escola as relações são marcadas pelo respeito.

Em seguida os estudantes realizaram uma aula prática investigativa pela escola com o intuito de observar o meio e responder as questões relacionadas no questionário (anexo 1).

O $3^{\circ}$ momento denominado aplicação dos conhecimentos teve como foco a finalização da série de atividades desenvolvidas sobre o tema, foram selecionadas 3 aulas onde os alunos 


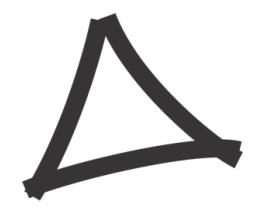

puderam sistematizar os conhecimentos adquiridos. Em grupos os estudantes confeccionaram cartazes e gráficos e expressaram por meio de desenhos esquemáticos seus conhecimentos sobre recursos naturais e sobre o meio ambiente.

Para finalizar propuseram ações para a escola visando à sustentabilidade, conforme quadro 2, os quais foram apresentados à Coordenação e demais alunos da escola.

\section{ANÁLISE DOS DADOS E RESULTADOS}

Na busca de soluções para os problemas ambientais é preciso conhecer as diferentes concepções de natureza presentes em determinadas sociedades e analisar como a natureza se faz presente para o homem.

Os resultados iniciais apontaram as concepções da maioria dos alunos sobre meio ambiente como "minha casa", essa concepção conforme Sauvé (2005) possui semelhança com a classificação meio ambiente como lugar que se vive. Segundo a autora o objetivo da Educação Ambiental é principalmente a relação que o sujeito tem com o meio ambiente (SAUVÉ, 2005).

As intervenções educativas foram desenvolvidas na tentativa de aproximar as relações entre sociedade e natureza numa perspectiva socioambiental por meio de uma abordagem interdisciplinar.

As estratégias utilizadas na Sequência Didática (roda de conversas, vídeo, filme, debates, aula prática investigativa, desenhos esquemáticos e exposição) proporcionaram interação entre os educandos e novos conhecimentos, elas foram facilitadoras do ensino aprendizado. Conforme Demo (2014) é preciso transformar a escola em laboratório de pesquisa e produção do conhecimento, favorecendo a formação de pesquisadores.

Por meio das práticas dialógicas pode-se perceber o olhar crítico dos alunos em relação aos novos conhecimentos, houve momentos de reflexão e discussão sobre algumas mudanças necessárias no estilo de vida e sobre a responsabilidade de cada um em relação ao 
meio ambiente. Percebeu-se também por meio de suas falas e ações o sentimento de pertencimento à natureza, o ser humano compreendido como um dos elementos da natureza.

As discussões com o tema Meio Ambiente nas instituições escolares devem contribuir para a formação de cidadãos conscientes, capazes de decidir e atuar socialmente no âmbito local e global (BRASIL, 2001).

Durante a aula prática investigativa os alunos refletiram e discutiram a fim de responder a questão: Sua escola pratica a sustentabilidade? Os gráficos (figura 1) confeccionados a partir dos dados obtidos pelos questionários (anexo 1) facilitaram a análise e a interpretação das questões sobre o ambiente escolar.

Figura 1 - Gráficos com resultados dos questionários Sua Escola pratica a Sustentabilidade?

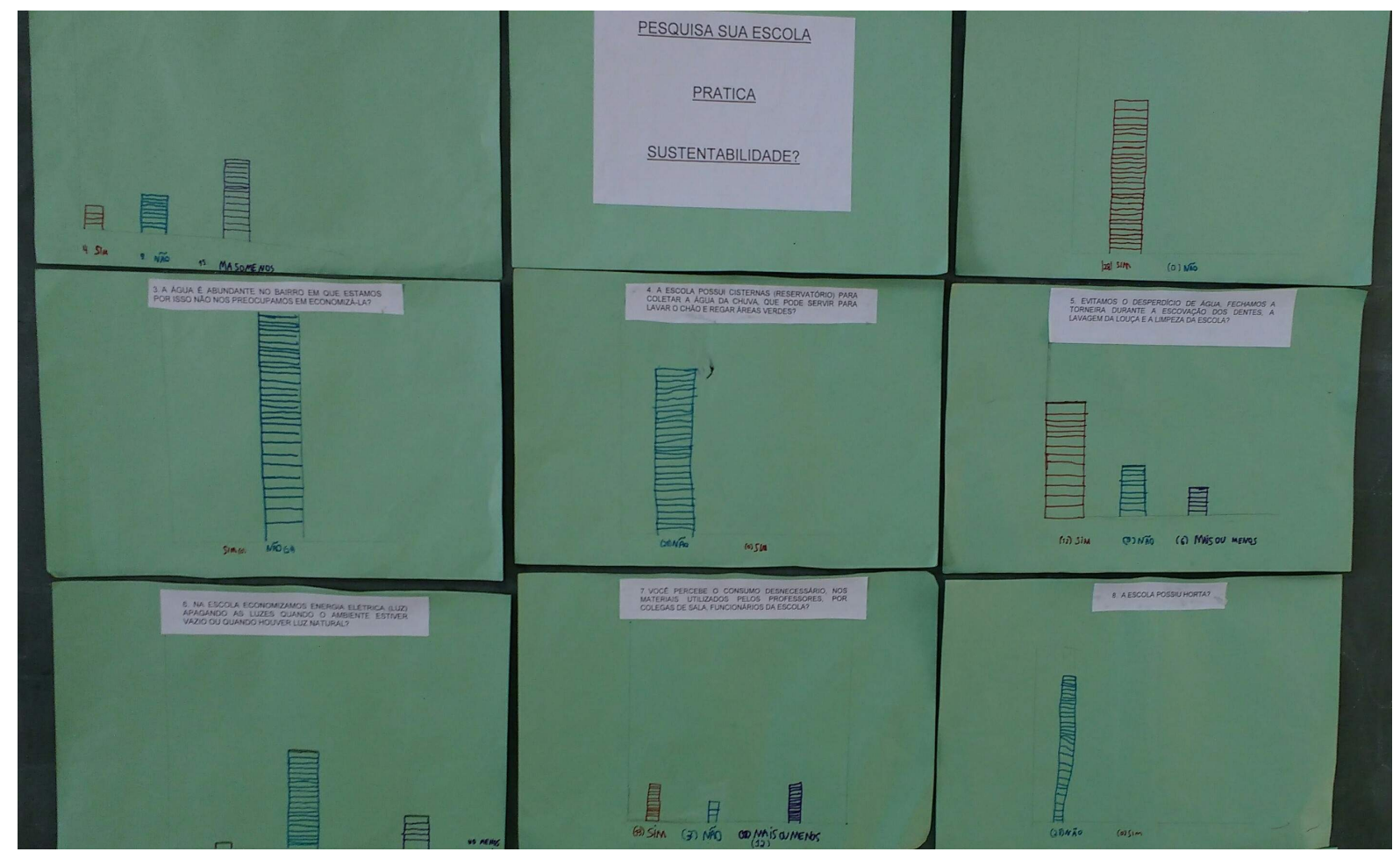

Fonte: Elaborada pelas pesquisadoras

Pela análise desses dados concluiu-se que a escola realiza algumas ações visando à sustentabilidade, tais como: reciclagem de resíduo seco, evita-se o desperdício de água durante a escovação dos dentes, as áreas verdes da escola são bem cuidadas, há uma composteira na escola. No entanto, ainda faz-se necessária a intensificação de algumas ações sobre as questões ambientais na escola. Assim, visando o fortalecimento da sustentabilidade, 
tanto na escola como em suas casas, os discentes propuseram algumas ações conforme quadro 2.

\section{Quadro 2 - Ações Propostas pelos alunos}

\begin{tabular}{|l|}
\hline Apagar as luzes quando não houver ninguém nas salas/banheiros (escola - casa) \\
\hline Instalação de interruptores nas salas de aula \\
\hline Pegar somente o que for comer para evitar desperdícios de alimentos (escola - casa) \\
\hline Fazer uma horta na escola \\
\hline Elaboração de cartazes para não haver desperdício de alimentos \\
\hline Evitar o desperdício de materiais (escola - casa) \\
\hline Divulgar a composteira para os demais alunos da escola \\
\hline Utilização dos latões instalados na escola para reciclagem (papel, plástico, vidro e metal) \\
\hline Instalação de cisternas para reaproveitamento da água da chuva (escola - casa) \\
\hline Fonte: Elaborada pelas pesquisadoras
\end{tabular}

Consideramos que o envolvimento dos alunos durante as atividades propostas foi decisivo para que a aprendizagem ocorresse de maneira significativa.

O processo educativo conforme Carvalho (2006) deve objetivar a formação do pensamento crítico e possibilitar aos sujeitos a realização de ações no coletivo e para o coletivo, visando à autonomia, a criatividade e a transformação da realidade, em prol de um ambiente ecologicamente equilibrado tendo o professor grande responsabilidade na formação do sujeito ecológico.

A fim de, orientar os demais alunos da escola sobre economia de energia elétrica, desperdício de alimentos e materiais, coleta seletiva, compostagem, construção de uma horta, foram confeccionados cartazes com desenhos esquemáticos, conforme figura 2 , e expostos na escola, proporcionando o início de um processo contínuo de melhoria da qualidade de vida e fortalecimento da cidadania da comunidade escolar. 
Figura 2 - Ações propostas pelos alunos
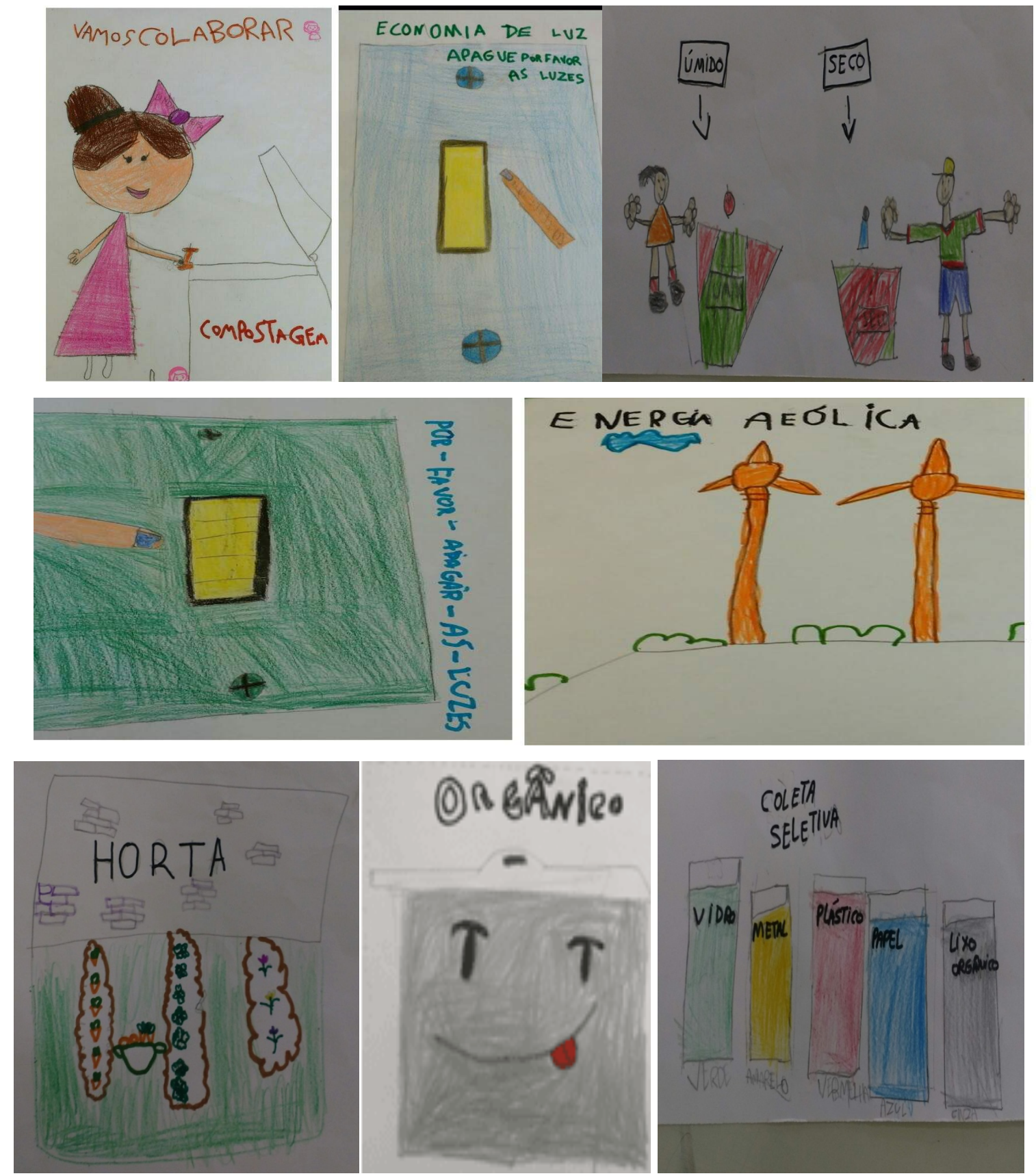

Fonte: Organizada pelas pesquisadoras

As produções dos desenhos proporcionaram a contextualização dos saberes adquiridos os quais foram expostos nos painéis da escola possibilitando a apreciação do conhecimento 
construído. Percebeu-se que os estudantes buscaram ações concretas e coerentes visando contribuir para formar uma coletividade responsável pelo ambiente em que habitam.

Os alunos apresentaram os resultados obtidos e as ações propostas à Coordenação Pedagógica e as demais turmas da escola, objetivando a divulgação da pesquisa (figura 3). Acreditamos ser fundamental fazer o levantamento dos problemas e propor ações, contudo, só serão convertidos em mudanças concretas com a mobilização de recursos humanos, financeiros, pedagógicos (BRASIL, 2012b).

Figura 3 - Apresentação dos resultados

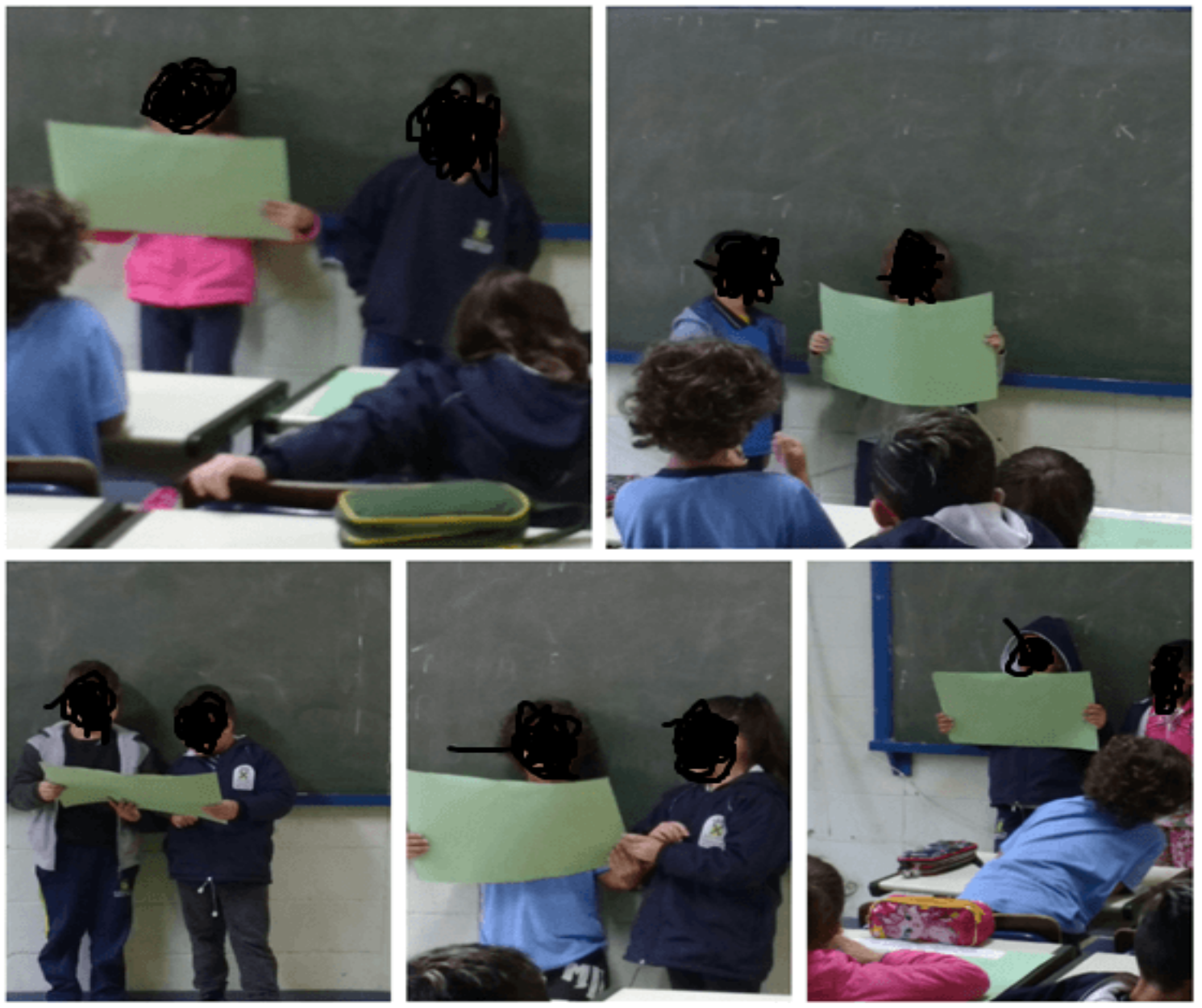

Fonte: Elaborada pelas pesquisadoras

Em seguida, para sistematização e fechamento das atividades foram propostos aos estudantes reflexões acerca de suas concepções iniciais sobre a temática abordada. Percebeu- 


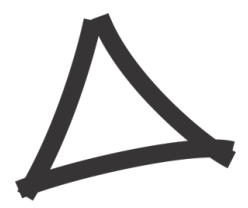

se o envolvimento do aluno e sua capacidade de agir em sociedade e de propor ações para transformar essa sociedade e redefinir sua própria condição na natureza.

A avaliação da Sequência Didática para a inserção da temática ambiental se deu de forma qualitativa e contínua, os estudantes foram avaliados por meio de sua participação nos questionamentos propostos; na organização das informações; nos argumentos presentes em registros e debates; em suas apresentações e produções. Vale ressaltar que a avaliação da ação deve considerar o processo educativo em si, transcendendo as práticas.

As atividades proporcionaram a reflexão e ação dos estudantes diante da problematização da realidade em que estão inseridos. A maioria dos educandos apresentaram mudanças significativas, tanto na escola como em suas casas, observou-se que já faz parte da rotina dos alunos ações sustentáveis, a fim de evitar o desperdício e diminuir o impacto ambiental.

Percebeu-se pelas falas de alguns alunos que as mudanças comportamentais ultrapassavam os muros da escola, o que consideramos fundamental, pois a escola não é a única responsável pela Educação Ambiental é importante à realização de um trabalho em conjunto, devendo estar presente nos diferentes espaços formais e não formais.

\section{CONSIDERAÇÕES FINAIS}

A Sequência Didática trabalhou a Educação Ambiental com alunos do $2^{\circ}$ ano do Ensino Fundamental (anos iniciais) de maneira crítica e comprometida com o exercício da cidadania. Contribuiu para a reflexão e construção de uma concepção de meio ambiente como sendo tudo que nos rodeia e as interações existentes entre indivíduo, sociedade e natureza.

A Educação Ambiental crítica é um processo dialógico que deixa de ser politicamente neutro, ele visa novos maneiras de se viver na natureza. A Educação Ambiental deve "buscar por transformação social, o que engloba indivíduos, grupos e classes sociais, culturas e estruturas, como base para a construção democrática de sociedades sustentáveis". (LOUREIRO; LEROY, 2011, p.112)

As relações dialógicas entre o educador e educandos e entre educandos e educandos propuseram momentos de ação-reflexão proporcionando a participação, a construção de

\begin{tabular}{l|l|l|l|l|l|l|} 
(C) Rev. Triang. & Uberaba, MG & v.11 & n.1 & p.196 - 211 & Jan./Abr. 2018 & ISSN 2175-1609
\end{tabular}




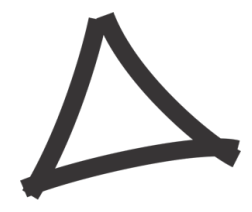

novas ideias, favorecendo a formação do pensamento crítico e a compreensão da realidade.

As atividades realizadas proporcionaram aos alunos momentos de ação e reflexão sobre suas responsabilidades e sobre ações a serem desenvolvidas no coletivo e para o coletivo.

Considerando as intervenções realizadas percebeu-se que os objetivos foram alcançados, pois a Sequência Didática proporcionou um ensino contextualizado e possibilitou aos estudantes refletir em relação aos problemas socioambientais (aumento populacional, consumismo e esgotamento dos recursos naturais). A atividade levou também a reflexão sobre a questão: Sua escola pratica a sustentabilidade? Proporcionou conhecimentos e transformou atitudes acerca de práticas cotidianas que causam desequilíbrios ambientais.

Embora a atividade aqui desenvolvida, apresente ações clássicas em Educação Ambiental ela mostrou que algumas metas ainda não foram alcançadas na escola. Ela abriu caminhos para novas ações, interpretações, comportamentos e para uma nova maneira do discente ver e viver no mundo. Concordamos com Sauvé (1997) quando cita que há necessidade de ampliação da discussão sobre o tema sustentabilidade, tendo em vista que é um assunto amplo e complexo (SAUVÉ, 1997).

Acreditamos que a atividade proporcionou aos alunos o desenvolvimento de um posicionamento crítico, sendo os mesmos capazes de refletir e discutir valores existentes em sua realidade.

Espera-se que a pesquisa possa desencadear questões sobre o pensar e agir da Educação Ambiental de maneira crítica. A atividade é colocada aqui como um ponto de partida para reflexões e ações, os desafios continuam e a abordagem do assunto não se deve esgotar com a finalização desta atividade.

\section{REFERÊNCIAS}

BRASIL. Lei de Diretrizes e Bases da Educação Nacional - LDB. Lei número 9394 de 20 de dezembro de 1996. 


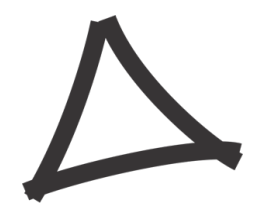

Revista Triângulo

www.seer.uftm.edu.br/revistaeletronica

BRASIL. Secretaria de Educação Fundamental. Parâmetros Curriculares Nacionais: Meio Ambiente. Secretaria de Educação Fundamental. Brasília, MEC/SEF, 1998.

BRASIL. Ministério da Educação o do Desporto. Parâmetros Curriculares Nacionais: Temas transversais. Brasília: MEC/SEF, 2001.

BRASIL. Secretaria de Educação Básica. Diretoria de Apoio à Gestão Educacional. Pacto nacional pela alfabetização na idade certa: alfabetização em foco: projetos didáticos e sequências didáticas em diálogo com os diferentes componentes curriculares. Ano 03 unidade 06. Ministério da Educação, Secretaria de Educação Básica, Diretoria de Apoio à Gestão Educacional. - Brasília: MEC, SEB, 2012a.

BRASIL. Secretaria de Educação Continua da Alfabetização, Diversidade e Inclusão. Vamos cuidar do Brasil com escolas sustentáveis: educando-nos para pensar e agir em tempos de mudanças socioambientais globais. Ministério da Educação, Secretaria de Educação Continuada, Alfabetização, Diversidade e Inclusão, Ministério do Meio Ambiente; elaboração de texto: Tereza Moreira. Brasília: MEC, SECADI, 2012 b.

CARVALHO, Isabel Cristina de Moura. Educação ambiental: a formação do sujeito ecológico. 2. ed. São Paulo: Cortez, 2006.

CUNHA, Beatriz Monteiro da. Os heróis e o consumo consciente. São Paulo, Evoluir, 2011.

DEMO, Pedro. Educação Científica. Revista Brasileira de Iniciação Científica. V. 1, n.1, Maio/2014.

DIAS, Genebaldo Freire. Educação ambiental: princípios e práticas. 7. ed., São Paulo: Gaia, 2010. p. 75-92.

GUIMARÃES, Mauro. A dimensão ambiental na educação. Campinas, SP: Papirus, 2015. 
LOUREIRO, Carlos Frederico Bernardo. Educação ambiental e movimentos sociais na construção da cidadania ecológica e planetária. In: LOUREIRO, C. F. B.; LAYRARGUES, P. P; CASTRO, R. S. (Orgs.). Educação ambiental: repensando o espaço da cidadania. 5. ed. São Paulo: Cortez, 2011.p. 73-103.

LOUREIRO, Carlos Frederico Bernardo. Problematizando conceitos: contribuição à práxis em educação ambiental. In: In: LOUREIRO, C. F. B.; LAYRARGUES, P. P; CASTRO, R. S. (Orgs.). Pensamento Complexo, Dialética e Educação Ambiental. 2. ed. São Paulo: Cortez, 2011. cap.4, 104-161.

REIGOTA, Marcos. O que é educação ambiental. São Paulo: Brasiliense, 2015.

SAUVÉ, Lucie. Educação Ambiental e desenvolvimento sustentável: uma análise complexa. Revista Educação Pública, Cuiabá, MT, v. 6, n. 10, jul./dez. 1997. Disponível em:. http://www.ufmt.br/revista/arquivo/rev10/educacao_ambiental_e_desenvolvim.html. Acesso em 25.abril.2017.

SAUVÉ, Lucie. Uma cartografia das correntes em educação ambiental. In: SATO, Michele, CARVALHO, Isabel C. Moura.(Orgs.). Educação Ambiental. Porto Alegre: Artmed, 2005, p.17-44.

ZABALA, Antoni. A prática pedagógica: como ensinar. Porto Alegre, Artmed, 2010. 
Anexo 1-Questionário

\begin{tabular}{|c|c|}
\hline \multicolumn{2}{|r|}{ Sua Escola pratica a Sustentabilidade? } \\
\hline Questão & Perguntas \\
\hline 1 & $\begin{array}{l}\text { A escola faz reciclagem do lixo. Separa os resíduos secos dos resíduos úmidos? } \\
\begin{array}{llll}\text { ( ) Sim } & \text { ( ) Não } & (\text { ) Mais ou menos }\end{array}\end{array}$ \\
\hline 2 & $\begin{array}{l}\text { A escola faz compostagem com os restos de alimentos/comida? } \\
\text { ( ) Sim ( ) Não }\end{array}$ \\
\hline 3 & $\begin{array}{l}\text { A água é abundante no bairro em que estamos por isso não nos preocupamos em } \\
\text { economizá-la? } \\
\begin{array}{lll}\text { ( ) Sim } & \text { ( ) Não }\end{array}\end{array}$ \\
\hline 4 & $\begin{array}{l}\text { A escola possui cisternas (reservatório) para coletar a água da chuva, que pode } \\
\text { servir para lavar o chão e regar as áreas verdes? } \\
(\text { ) Sim ( ) Não }\end{array}$ \\
\hline 5 & $\begin{array}{l}\text { Evitamos o desperdício de água, fechamos a torneira durante a escovação dos } \\
\text { dentes, a lavagem da louça e a limpeza da escola? } \\
\begin{array}{lll}\text { ( ) Sim } & \text { ( ) Não } & (\text { ) Mais ou menos }\end{array}\end{array}$ \\
\hline 6 & $\begin{array}{l}\text { Economizamos energia elétrica (luz) apagando as luzes quando o ambiente estiver } \\
\text { vazio ou quando houver luz natural? } \\
\left(\begin{array}{l}\text { ) Sim ( ) Não ( ) Mais ou menos }\end{array}\right.\end{array}$ \\
\hline 7 & 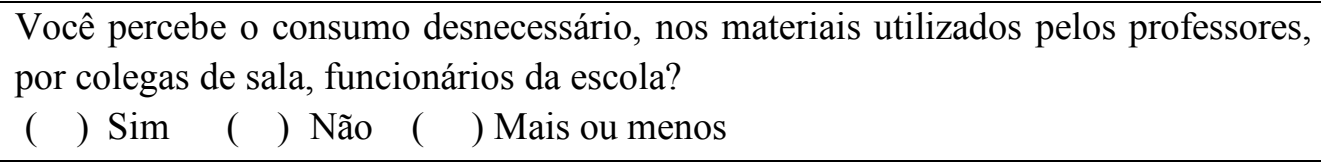 \\
\hline 8 & $\begin{array}{l}\text { A escola possui horta? } \\
\left(\begin{array}{l}\quad) \operatorname{Sim} \quad(\quad) \text { Não }\end{array}\right.\end{array}$ \\
\hline 9 & 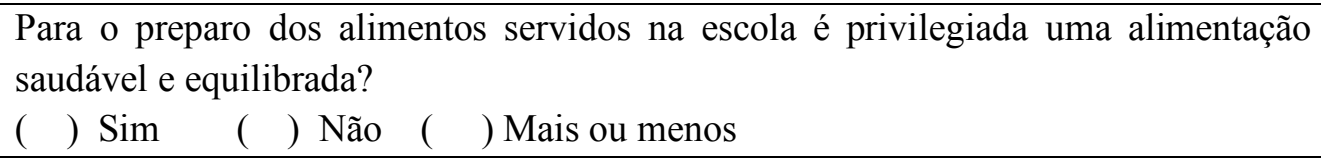 \\
\hline 10 & $\begin{array}{l}\text { Há desperdício de alimentos servidos na escola? } \\
\left(\begin{array}{l}\text { ( ) Sim ( ) Não }\end{array}\right.\end{array}$ \\
\hline 11 & $\begin{array}{l}\text { Cuidamos das áreas verdes internas da escola? } \\
\text { ( ) Sim ( ) Não ( ) Mais ou menos }\end{array}$ \\
\hline 12 & $\begin{array}{l}\text { As relações entre alunos, professores, gestores, demais funcionários e familiares são } \\
\text { marcadas pelo respeito? } \\
\begin{array}{lll}\text { ( ) Sim } & \text { ( ) Não } & \text { ( ) Mais ou menos }\end{array}\end{array}$ \\
\hline
\end{tabular}

